\title{
Colloidal micro- and nano-particles as templates for polyelectrolyte multilayer capsules
}

\author{
Bogdan V. Parakhonskiy ${ }^{\text {a,b }}$, Alexey M. Yashchenok ${ }^{c}$, Manfred Konrad ${ }^{\text {d }}$, Andre G. Skirtach ${ }^{\text {cee,* }}$ \\ a BIOtech Center, Department of Physics, University of Trento, via delle Regole 101, 38123 Mattarello, Italy \\ b Shubnikov Institute of Crystallography, Russian Academy of Science, Leninskii prospekt 59, Moscow 119333, Russia \\ c Department of Interfaces, Max-Planck Institute of Colloids and Interfaces, Golm, Potsdam D-14476, Germany \\ d Enzyme Biochemistry Laboratory, Max Planck Institute for Biophysical Chemistry, D-37077 Gottingen, Germany \\ e Department of Molecular Biotechnology E' Nano-Bio (NB)-Photonics, Ghent University, 9000 Ghent, Belgium
}

\section{A R T I C L E I N F O}

Available online 10 February 2014

\section{Keywords:}

Microcapsules

Colloidal particles

Templates

Polyelectrolytes

Multilayers

\begin{abstract}
A B S T R A C T
Colloidal particles play an important role in various areas of material and pharmaceutical sciences, biotechnology, and biomedicine. In this overview we describe micro- and nano-particles used for the preparation of polyelectrolyte multilayer capsules and as drug delivery vehicles. An essential feature of polyelectrolyte multilayer capsule preparations is the ability to adsorb polymeric layers onto colloidal particles or templates followed by dissolution of these templates. The choice of the template is determined by various physico-chemical conditions: solvent needed for dissolution, porosity, aggregation tendency, as well as release of materials from capsules. Historically, the first templates were based on melamine formaldehyde, later evolving towards more elaborate materials such as silica and calcium carbonate. Their advantages and disadvantages are discussed here in comparison to non-particulate templates such as red blood cells. Further steps in this area include development of anisotropic particles, which themselves can serve as delivery carriers. We provide insights into application of particles as drug delivery carriers in comparison to microcapsules templated on them.
\end{abstract}

(C) 2014 Elsevier B.V. All rights reserved.

\section{Contents}

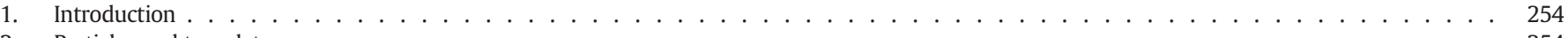

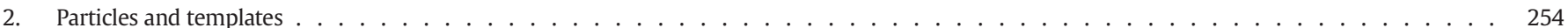

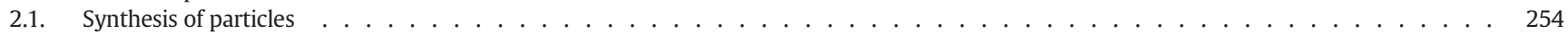

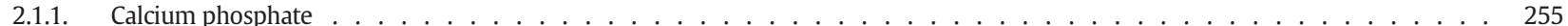

2.1.2. Calcium carbonate $\left(\mathrm{CaCO}_{3}\right) \ldots \ldots \ldots \ldots \ldots \ldots$

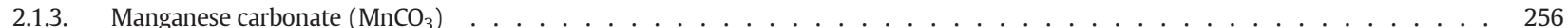

2.1.4. Cadmium carbonate $\left(\mathrm{CdCO}_{3}\right) \ldots \ldots \ldots \ldots \ldots$

2.1.5. Synthesis of dextran-hydroxyethyl methacrylate (dex-HEMA) microgels . . . . . . . . . . . . . . . . . . . . . . 256

2.1.6. Fabrication of alginate hydrogel microspheres $\ldots \ldots \ldots \ldots \ldots$

2.1.7. Formation of mesoporous silica particles . . . . . . . . . . . . . . . . . . . . . . . 256

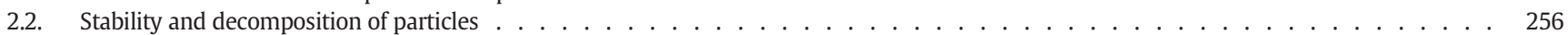

2.3. Release from particles . . . . . . . . . . . . . . . . . . . . . . . . . . . . . 256

2.3.1. Release by recrystallization at normal $\mathrm{pH} \ldots \ldots \ldots \ldots \ldots$

2.3.2. Release at low $\mathrm{pH} \ldots \ldots \ldots \ldots \ldots \ldots$

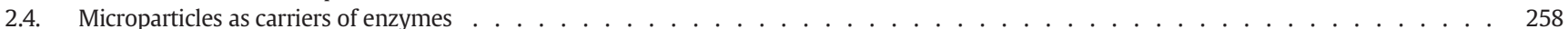

2.5. Biomolecule-based particles . . . . . . . . . . . . . . . . . . . . . . . . . . . . . . . . . . . . . . . . . . . 259

3. Capsules

3.1. From particles to capsules: dissolution of templates $\ldots \ldots \ldots \ldots$

3.2. Release of cargo from capsules . . . . . . . . . . . . . . . . . . . . . . . . . . . . . . . 260

4. Complex morphologies of particles and capsules $\ldots \ldots \ldots \ldots$

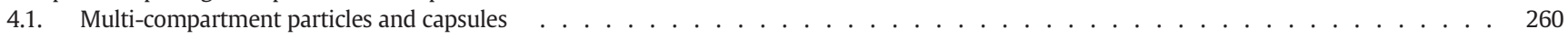

4.2. Anisotropic capsules and anisotropic carriers . . . . . . . . . . . . . . . . . . . . . . . . . . . . . . 261

\footnotetext{
* Corresponding author at: University of Ghent, Belgium.

E-mail address: Andre.Skirtach@UGent.be (A.G. Skirtach).
} 


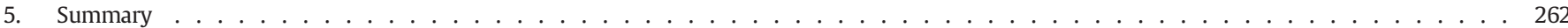

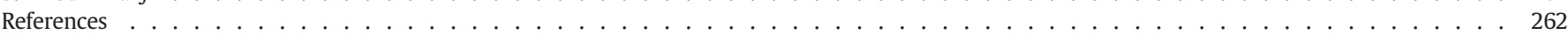

\section{Introduction}

The significance of micro- and nano-particles ranges from early developments in the area of colloidal particles to a broad range of industrial and nanotechnology applications in physical, biological, and medical sciences. In this overview, we focus on the class of organic and inorganic particles which are used as templates for the preparation of polyelectrolyte multilayer capsules. The choice of the template for the preparation of these capsules is particularly important in different fields of application, with advantages and disadvantages pertaining to the template dissolution, the stability of the polymer shell, and tendency to aggregation. In addition, these particles can serve as drug delivery carriers themselves.

There are two important classes of templates, possessing either smooth or porous surface. The surface porosity of templates determines a number of parameters of polyelectrolyte multilayer capsules, including the easiness of preparation, polymer shell thickness, and efficiency of loading of molecules. For example, smooth particles usually need the addition of more layers of the polyelectrolytes, and the shell wall is quite thin, on the order of one to two nanometers. The interior of such capsules is typically clean and transparent, and after dissolution of the core particle, such capsules look like empty balloons. On the contrary, during the layer-by-layer ( $\mathrm{LbL}$ ) adsorption on porous cores, the polyelectrolytes penetrate into the matrix, resulting in a substantially thicker polymer shell. In this case, the capsules look like sponges after the core dissolution. This differential property is very important for loading of molecules and for protection of encapsulated materials. For the capsules templated on porous particles, pores are utilized for loading producing relatively large capacity. Polyelectrolyte capsules based on smooth particles have a bigger inner volume, can easily encapsulate substances by heating and thereby shrinking of surface, and release of cargo from such particles can be more easily manipulated by external stimuli.

Colloidal particles used directly as carriers represent an important class of materials and stand on their own in various areas of research.
We elaborate here on the applicability and potential role of particles as templates for the preparation of polyelectrolyte multilayer capsules on one hand, and as stand-alone carriers on the other hand.

\section{Particles and templates}

\subsection{Synthesis of particles}

A number of different particles are used as templates for the preparation of polyelectrolyte multilayer capsules. Information about particles most frequently used for the fabrication of polymeric capsules is summarized in Table 1. Templates can be divided into two major classes, namely smooth and porous particles. The smooth ones encompass, for example, melamine-formaldehyde, silica, and polystyrene. Most of them are commercially available in a large range of sizes: from approximately $100 \mathrm{~nm}$ to millimeters. Advantages of these particles include good stability (zeta-potential of $\sim 35 \mathrm{mV}$ ) and excellent monodispersity. Specific modifications of the surface of these particles with amino-, carboxy-, mercapto-, maleimido-, hydroxy-, epoxy-, sulfo-, and other functional groups are available. The tailored properties of particles allow extending their potential application to medical diagnostics, pharmaceutical industry, biotechnology, molecular biology, analytics, etc. For drug delivery purposes, these types of particles are of limited use due to low loading efficacy on the functionalized surface. The most advanced approach consists in the loading of the hollow polymeric shell which is obtained when the solid core is decomposed, Fig. 1.

Porous particles constitute another type of solid particles. They have a number of advantages over their smooth counterparts, including facile synthesis, low cost of processing, and high porosity which leads to an increased loading capacity. The relatively big variation in size (polydispersity) and strong aggregative behavior are some disadvantages of this type of templates. Production of porous particles (calcium carbonate) is relatively easy, including the mixing of two salt solutions either in the absence or in the presence of special additives which are used to obtain certain surface modifications or a particular morphology.

Table 1

Types and sizes of particles, and chemicals used for their decomposition in the construction of polymeric capsules.

\begin{tabular}{|c|c|c|c|}
\hline Type of the particles & Size of the particles used as templates for polyelectrolyte capsules, microns & Size range, microns & Solvent \\
\hline \multicolumn{4}{|l|}{ Smooth particles } \\
\hline Silica & $0.5[2] 1[2], 1.9[3], 4.5-5[4-7]$ & $2-5$ & $\mathrm{HF}, \mathrm{HF} / \mathrm{NH}_{4} \mathrm{~F}$ \\
\hline Melamine-formaldehyde & $1[8], 2[9,10] 3.2-3.5[8,11,12], 4.2[13], 5-5.7[14-16]$ & $3.2-5.7$ & $\begin{array}{l}\mathrm{HCl}, \mathrm{N}, \mathrm{N}-\text { dimethylformamide (DMF) or } \\
\text { dimethyl sulfoxide (DMSO). }\end{array}$ \\
\hline Polystyrene & $0.64[8] 4.4-4.6[5,17,18], 9.6-10.6[19,20] 20[20]$ & $4-20$ & THF \\
\hline $\mathrm{CdCO}_{3}$ cubic shape & $2.5,4-6[21]$ & $2.5-6$ & $\mathrm{HCl}, \mathrm{pH}=1$ \\
\hline $\mathrm{CaCO}_{3}$ cubic shape & $4-5[22]$ & $4-5$ & $\mathrm{HCl}, \mathrm{EDTA}$ \\
\hline Calcium phosphate modified by $\mathrm{PAH}$ & $158-300 \mathrm{~nm}[23]$ & $0.16-0.3$ & $\mathrm{HCl}$ \\
\hline Gold nanoparticles & $13.5 \mathrm{~nm}[24]$ & 0.14 & Potassium cyanide \\
\hline Micro gel dex-HEMA & $150[25]$ & 150 & $\mathrm{NaOH}$ solution \\
\hline Alginate hydrogel microspheres & $4.25[26]$ & 4.25 & \\
\hline poly-DL-lactic acid particles (PLA) & $4-8[10]$ & $4-8$ & $\begin{array}{l}\text { 1:1 mixture of 1-methyl-2-pyrrolindinone } \\
\text { acid and organic solvent (acetone) }\end{array}$ \\
\hline Halloysite & Cylinder $50 \mathrm{~nm} \times 300 \mathrm{~nm}$ [27] & $0.05 \times 0.3$ & \\
\hline \multicolumn{4}{|l|}{ Porous particles } \\
\hline Mesoporous silica & $0.4[28], 2-4[1,29]$ & $0.4-4$ & $\mathrm{HF}, \mathrm{HF} / \mathrm{NH}_{4} \mathrm{~F}$ \\
\hline Calcium carbonate spherical & $4-5[18,22,30,31], 9[32], 11.5[33]$ & $4-11.5$ & EDTA $\mathrm{pH}$ 6; acid solution $\mathrm{pH}<6$ \\
\hline $\mathrm{MnCO}_{3}$ & 1.9.[9] 2.5-2.8 [9,34], $3.6[32], 5-5.5[35,36]$ & $2.8-5.5$ & \\
\hline Calcium carbonate elliptic & $2-4[22]$ & $2-4$ & EDTA pH 6; acid solution $\mathrm{pH}<6$ \\
\hline \multicolumn{4}{|l|}{ Hybrid templates } \\
\hline Human erythrocytes & $5-6[37-42] 5-6[37-42]$ & $5-6$ & $140 \mathrm{mM} \mathrm{NaCl}$ and $1.2 \% \mathrm{NaOCl}$ \\
\hline Virus-like particles & $\sim 4[43]$ & $\sim 4$ & \\
\hline Liposomes & $0.1-0.5[44]$ & $0.1-0.5$ & \\
\hline
\end{tabular}




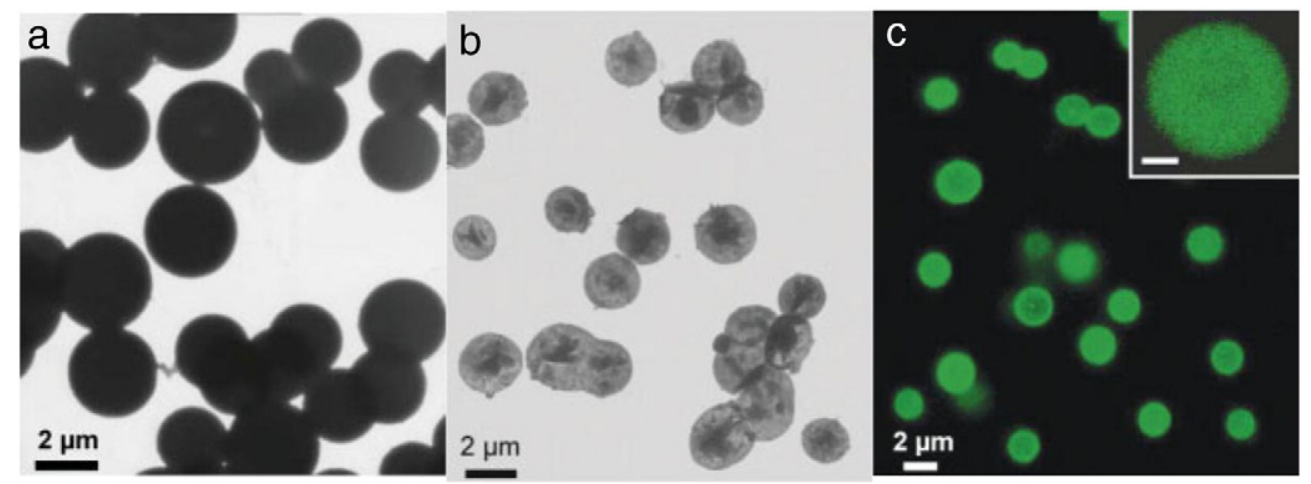

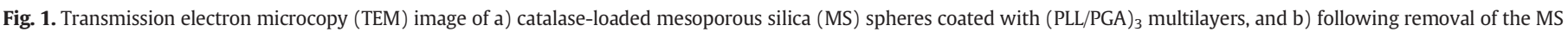

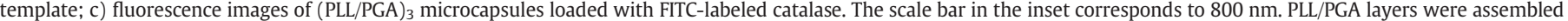
from a $0.05 \mathrm{M}$ MES, pH 5.5 buffer. The MS spheres were dissolved using $\mathrm{HF} / \mathrm{NH}_{4} \mathrm{~F}$ at $\mathrm{pH}=5$. Figure reprinted from [1]. Copyright Wiley-VCH Verlag GmbH \& Co. KGaA.

\subsubsection{Calcium phosphate}

Calcium phosphate synthesis usually involves mixing of two salt solutions to initiate crystal growth. Calcium phosphate precipitates form as a result of colloidal aggregation during mixing of $\mathrm{CaCl}_{2}$ and $\mathrm{Na}_{2} \mathrm{HPO}_{4}$ in a buffer solution (TRIS pH 7.4) [45]. The PAH-modified nanoparticles of calcium phosphate were prepared at room temperature by rapidly pumping aqueous solutions of calcium lactate, $\left(\mathrm{NH}_{4}\right)_{2} \mathrm{HPO}_{4}$, and poly(allylamine hydrochloride)( $\left.\mathrm{PAH}\right)$ in a volume ratio of 1:1:1 into 4 volume parts of water, forming particles with diameter of about $158 \mathrm{~nm}$ [23]. Another approach for the synthesis of smaller calcium phosphates nanoparticles $(20 \mathrm{~nm})$ was proposed by Y. Cai [46]: $\mathrm{A} \mathrm{CaCl}_{2}$ solution was dropwise added to a $\mathrm{Na}_{2} \mathrm{HPO}_{4}$ solution containing different concentrations of hexadecyl(cetyl) trimethyl ammonium bromide (CTAB) in magnetically stirred vessels at $20^{\circ} \mathrm{C}$.

\subsubsection{Calcium carbonate $\left(\mathrm{CaCO}_{3}\right)$}

Synthesis of calcium carbonate templates is based on crystal growth of polycrystalline spherical vaterite particles precipitated by mixing of $\mathrm{CaCl}_{2}$ and $\mathrm{Na}_{2} \mathrm{CO}_{3}$ solutions [47]. The nucleation and growth rate of

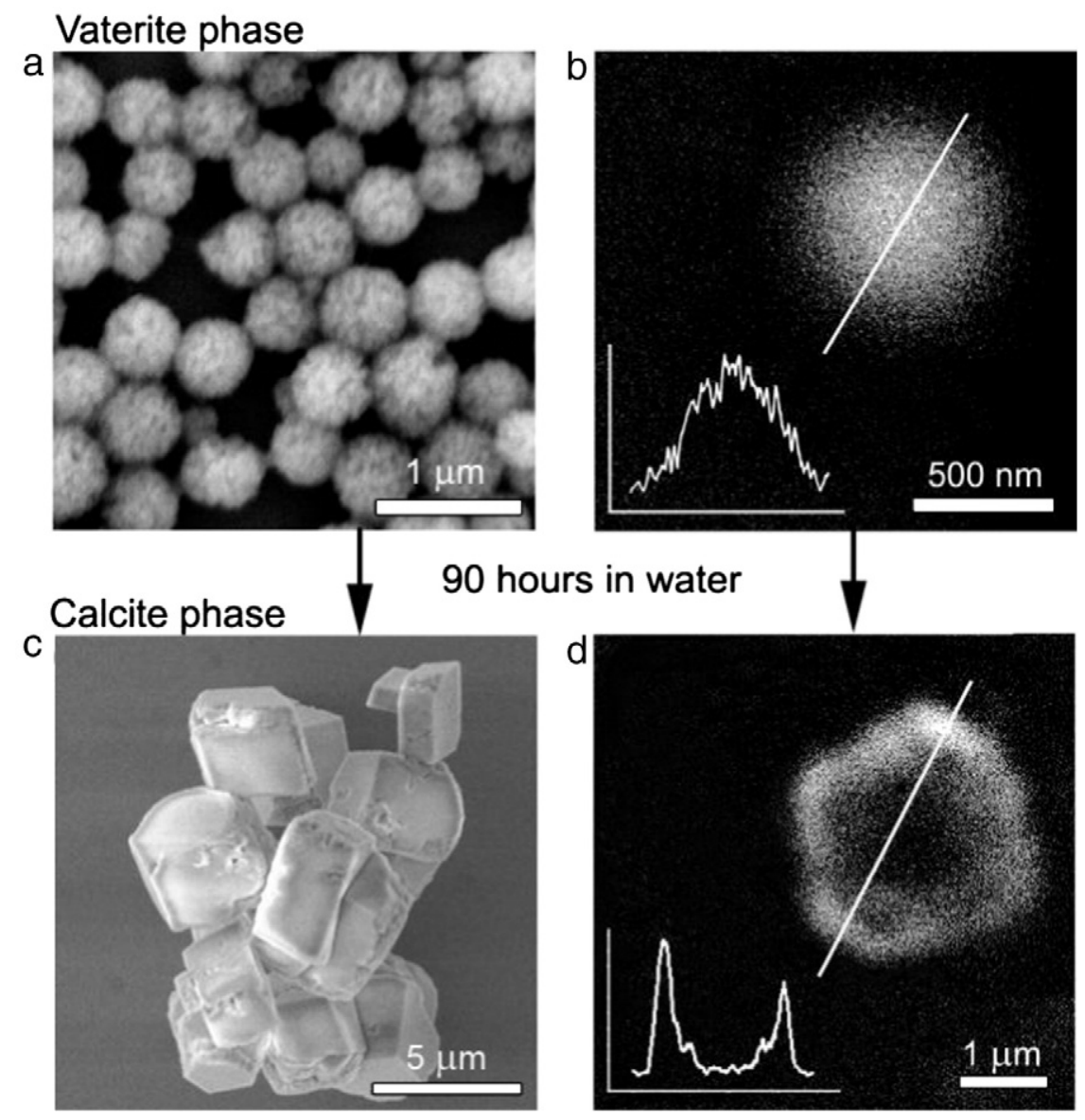

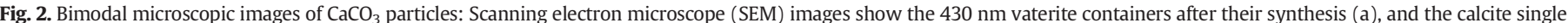

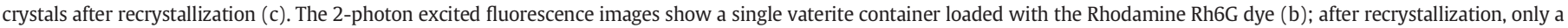

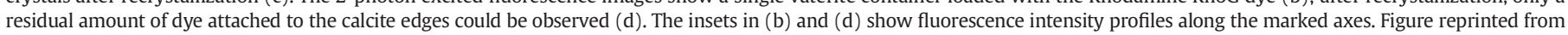
[50]. Copyright Wiley-VCH Verlag GmbH \& Co. KGaA. 
the vaterite particles is determined by the supersaturation level of the dissolved amorphous $\mathrm{CaCO}_{3}$ [48]. The final size of the vaterite particles depends strongly on the concentration of the reagents, the solubility of the salts, the reaction time, and the rotation speed during mixing. It was shown that at high salt concentrations $(1 \mathrm{M})$, at stirring rates of up to $1500 \mathrm{rpm}$, and reaction time of about $2 \mathrm{~min}$, the size of $\mathrm{CaCO}_{3}$ particle was reduced to $3 \mu \mathrm{m}$ [49]. Recently, size control of spherical vaterite particles in the range from 10 down to $0.4 \mu \mathrm{m}$ (Fig. 2a) has been achieved in a mixture of water and ethylene glycol (EG) [50]. The presence of EG during synthesis of $\mathrm{CaCO}_{3}$ particles diminishes the molecular diffusion, reduces the rate and the probability of nucleation, which leads to stabilization of the particles. Depending on the size of the particles, the pore size can be varied from $10 \mathrm{~nm}$ to $60 \mathrm{~nm}$. Thus, with pore sizes well above $10 \mathrm{~nm}$, the $\mathrm{CaCO}_{3}$ particles are not nanoporous, but can be considered mesoporous [51]. In $430 \mathrm{~nm}$ vaterite particles, the average pore size is $\sim 30 \mathrm{~nm}$ [52], in $4 \mu \mathrm{m}$-particles it is $\sim 35 \mathrm{~nm}$, and $18 \mu \mathrm{m}$-particles have a pore size distribution ranging from 20 to $60 \mathrm{~nm}$ [51]. Thus, it appears that upon decreasing the size of the particles to less than $4 \mu \mathrm{m}$, the pore size reaches an average value of $30-35 \mathrm{~nm}$. Biocompatibility tests for vaterite particles indicated no cytotoxicity and no influence on viability or metabolic activity [52].

\subsubsection{Manganese carbonate $\left(\mathrm{MnCO}_{3}\right)$}

The procedure for manganese carbonate particles synthesis is similar to calcium carbonate synthesis described before, using salt solutions which contain appropriate ions [21] The acidic manganese sulfate solution is added to $\mathrm{NH}_{4} \mathrm{HCO}_{3}$ in a volume ratio of $1: 1$, the stirred mixture is then aged at $50{ }^{\circ} \mathrm{C}$ for $16 \mathrm{~h}$. The resulting $\mathrm{MnCO}_{3}$ particles have round shapes, and their diameters range from $1.85 \mu \mathrm{m}$ to $0.3 \mathrm{~mm}$ [9].

\subsubsection{Cadmium carbonate $\left(\mathrm{CdCO}_{3}\right)$}

This type of particles is often prepared according to the method described by Janekovic and Matijevic [53]. A $10 \mathrm{M}$ urea solution aged for 24 $\mathrm{h}$ at $80{ }^{\circ} \mathrm{C}$ is quickly added to a preheated $20 \mathrm{mM} \mathrm{CdSO}_{4}$ solution. This procedure leads to monodisperse cubic $\mathrm{CdCO}_{3}$ crystals with a linear size of about $2.5 \mu \mathrm{m}$. Temperature has been found to be critical for the shape of the $\mathrm{CdCO}_{3}$ crystals. Thus, in the range of temperatures used $\left(70-75^{\circ} \mathrm{C}\right)$, large polydisperse spherical $\mathrm{CdCO}_{3}$ particles $(4-6 \mu \mathrm{m})$ are formed [21].

\subsubsection{Synthesis of dextran-hydroxyethyl methacrylate (dex-HEMA) microgels}

Dex-HEMA was slowly introduced with a pipette into a PEG solution under slow continuous stirring in a glass beaker. Upon formation of a homogeneous dispersion, $35 \mathrm{ml}$ dimethyl aminoethyl methacrylate (DMAEMA) was added, and the mixture was slowly stirred for $1 \mathrm{~min}$. In the next step, radical polymerization was started by addition of $\mathrm{N}, \mathrm{N}$, $\mathrm{N}^{\prime}, \mathrm{N}^{\prime}$-tetramethylethylenediamine (TEMED) (100 ml; pH neutralized by $4 \mathrm{M} \mathrm{NaCl}$ ) and potassium persulfate (KPS). The mixture was stirred for $15 \mathrm{~min}$, and then allowed to stand for $30 \mathrm{~min}$. The resulting microgels were centrifuged/washed with $20 \mathrm{ml}$ water (twice) and stored in $5 \mathrm{ml}$ water at $20{ }^{\circ} \mathrm{C}$ [25].

\subsubsection{Fabrication of alginate hydrogel microspheres}

An emulsification method was used for the preparation of alginate hydrogel microspheres. Briefly, $50 \mathrm{~g}$ of $3 \mathrm{wt}$.\% sodium alginate aqueous solution was dispersed in $75 \mathrm{~g}$ of isooctane containing $1.7 \mathrm{~g}$ of the surfactant SPAN 85 (sorbitan trioleate) using an ultrasonicator at $60 \%$ power for $5 \mathrm{~min}$. A solution containing $0.9 \mathrm{~g}$ of TWEEN 85 (polyoxyethylene sorbitan trioleate) in $5 \mathrm{~g}$ of isooctane was then added to the emulsion and ultra-sonicated at the same power for another $5 \mathrm{~min}$ to achieve stable water/oil emulsion droplets. Following this step, $20 \mathrm{~mL}$ of aqueous solution containing $10 \mathrm{wt} . \%$ of calcium chloride was added. The microspheres were then rinsed three times with deionized water by centrifugation.

\subsubsection{Formation of mesoporous silica particles}

The reaction mixture for the synthesis of mesoporous silica particles was prepared directly in an autoclavable polypropylene bottle at $\sim 30{ }^{\circ} \mathrm{C}$. A total of $19.6 \mathrm{~g}$ of CTAB followed by $10 \mathrm{~g}$ of solid $\mathrm{Na}_{2} \mathrm{SiO}_{3}$ were dissolved in $350 \mathrm{ml}$ of distilled water, resulting in a clear solution. Then, $25 \mathrm{ml}$ of ethyl acetate were quickly added under stirring. After $30 \mathrm{~s}$, the stirring was stopped, and the mixture was allowed to stand at ambient temperature for $5 \mathrm{~h}$; after this period of aging, the $\mathrm{pH}$ reached a constant value. During the aging process, organic solvents were allowed to evaporate through leaks in the cap of the bottle. The resulting solids were recovered by filtration of the warm reaction mixture, extensively washed with distilled water and ethanol, and dried at ambient temperature. The template was removed by calcination at $600{ }^{\circ} \mathrm{C}$ for $20 \mathrm{~h}$ in flowing air [54].

\subsection{Stability and decomposition of particles}

The most important parameter of colloidal systems is the stability of particles which depends on the degree of ion adsorption, and, therefore, on the zeta potential. The smooth particles melamine-formaldehyde, silica, and polystyrene have relative high zeta-potentials $(\sim 50 \mathrm{mV})$, and, therefore, high stability. The high surface charge prevents these particles from aggregation; furthermore, their morphology is unchangeable.

In contrast to smooth particles, porous ones, for example $\mathrm{CaCO}_{3}$, are not stable in aqueous solution or during extended steps of synthesis, and they transform to the more stable calcite structure [50]. Early studies have demonstrated the influence of aqueous and PBS buffer on $\mathrm{CaCO}_{3}$ morphology (Fig. 2c). In order to prevent recrystallization, particles can be either transferred to pure ethanol or dried at $70{ }^{\circ} \mathrm{C}$ during $1 \mathrm{~h}$ and then kept as a powder.

In contrast to the stability of the aforementioned particles, the decomposable ones can be treated to obtain polymeric hollow carriers by immersion into appropriate solvents. These chemicals are listed in Table 1. Depending on the material of the particles, the dissolution process lasts from several minutes to several hours, and this is followed by thorough washing with water. When using chemicals for dissolution of particles, caution should be taken into account, since in certain cases these may include acidic media or might have toxic effects. Specifically, silica particles usually are decomposed in $0.3 \mathrm{M}$ HF consisting of a mixture of $\mathrm{HF}$ and $\mathrm{NH}_{4} \mathrm{~F}$. N,N- dimethylformamide (DMF)/dimethyl sulfoxide (DMSO) and tetrahydrofuran (THF) have been used for melamineformaldehyde and polystyrene particles, respectively. Calcium carbonate particles have been found to dissolve by immersing them into acidic media, such as $\mathrm{NaCl} / \mathrm{HCl}$ buffer ( $\mathrm{pH} 2.0$ ), as well as by complexation with the chelating agent EDTA in appropriate solution ( $0.2 \mathrm{M}, \mathrm{pH} 7.5)$ $[31,55]$.

The gold core was removed and transformed in a gold cyanide complex according to Eq. (1).

$2 \mathrm{Au}+1 / 2 \mathrm{O}_{2}+\mathrm{H}_{2} \mathrm{O}+4 \mathrm{KCN} \rightarrow 2 \mathrm{~K}\left[\mathrm{Au}(\mathrm{CN})_{2}\right]+2 \mathrm{KOH}$

Red blood cells can be removed by exposure to a mixture of $140 \mathrm{mM}$ $\mathrm{NaCl}$ and $1.2 \% \mathrm{NaClO}$.

\subsection{Release from particles}

The release of biomolecules, such as small drug molecules from particles [56], is governed by an interplay of drug desorption and carrier dissolution [57]. This process usually is very slow, especially in the absence of a payload-specific solvent, but could be increased when the carrier size is reduced. During the desorption/adsorption process, molecules get detached and reattached until a dynamic equilibrium is reached, causing small oscillatory modulations in the release curve [57-59]. Furthermore, the particles themselves can be degraded or dissolved by the surrounding medium, causing the payload to diffuse from the carrier. 
The typical time-dependence of release from porous silica particles has been discussed earlier. The release is observed to be very fast during the first few hours (releasing up to 75\%), and then the release curve reaches saturation, with around $10 \%$ of encapsulated material remaining bound for longer time. This has been demonstrated for the release of doxorubicin from silica particles [60]; Brilliant Blue $\mathrm{F}$ from porous silica particles [61]; Orange 2, Rhodamine 6G, and doxorubicin encapsulated in millimeter-sized silicagel particles [62], and for gentamicin released over a period of 20 days from mesoporous silica [63].

When the particles start to dissolve, the release is enhanced and reaches $100 \%$ when all carriers are dissolved. [64]. This is commonly observed for biodegradable carriers such as the well-known gelatin, polyalginate capsules. One of the typical examples is poly(D,L-lacticco-glycolic) acid PLGA particles: Continuous release of serum albumin from biodegradable PLGA particles during 60 days has been demonstrated [65]. Also, a number of particles based on carbonate and gelatin can dissolve at low $\mathrm{pH}$ in the stomach, and cargo is rapidly released.

\subsubsection{Release by recrystallization at normal $\mathrm{pH}$}

The combination of dissolution and desorption processes is a unique property of slowly dissolving crystals, or it happens during recrystallization of the containers. This effect can be seen on the calcium carbonate particles in the vaterite phase. The vaterite particles (Fig. 3a) can dissolve or can get transferred into a crystal phase (to calcite, Fig. 3b), where the external layer of vaterite starts to ionize [55]. The simultaneous occurrence of the two processes (desorption and dissolution) offers the opportunity to realize the delayed burst release.

In previous work [52], the authors demonstrated the release based on this process and studied it for encapsulated cargo of different sizes: for high molecular weight tetramethyl-rhodamine isothiocyanate TRITCdextran [52], for the low molecular weight model substance Rhodamine $6 G$ [52,66], and for the drug photosensitizer "Photosens" (a mixture of sulfonated aluminum phthalocyanines AlPcSn, with $n=2,3$ or 4) [55]. The size of particles can vary between $400 \mathrm{~nm}$ and $4 \mu \mathrm{m}$. Typically, the recrystallization process starts when vaterite particles are immersed in an aqueous solution: This formation of particles can be explained by the dissolution and ionization of the external layer of vaterite [67].

Particles can be loaded with molecules of low molecular weight (e.g. Rhodamine Rh6G). The dye is slowly released until equilibrium is reached. An interesting feature is that after three to four days, the recrystallization process accelerates, raising the amount of dye molecules in the aqueous solution to $40 \%$. The complete recrystallization of all vaterite spheres takes place within less than one week (Fig. 3c).

Immersion of the vaterite particles in ethanol induces slow release via adsorption-desorption. The total amount of released dye was reported to be around $22 \%$ after one day, and did not increase significantly during one week of monitoring. This points to the formation of the desorption-adsorption equilibrium without crystal phase transition. Colloidal stability of containers results from their high negative Z-potential. For particles loaded with high molecular weight molecules, no recrystallization was observed regardless of the media used (experiments lasted for one week). In this time-frame, only slow release is possible, while recrystallization is expected to end after one week, possibly due to strong attachment of TRITC-dextran to the surface of vaterite. This view is supported by the observed strong negative Z-potential, which is thought to prevent aggregation; in addition, TRITC-dextran slows down the rate of carrier dissolution. $[68,69]$. Thorough understanding of these mechanisms can be used to tune the release dynamics.

\subsubsection{Release at low $\mathrm{pH}$}

Dissolution of calcium carbonate containers at $\mathrm{pH}<5$ was used for creating the matrix of encapsulated drug [70], or for simple release of the compound [66]. This $\mathrm{pH}$-dependence of the dissolution of particles avails to adjust conditions for controlled and targeted cellular delivery. This is due to the fact that the microenvironment in tumors is typically more acidic than that in normal tissues [71]. Thus, during endocytosis, the $\mathrm{pH}$ level decreases in the endocytotic vesicles to around 5.0, in comparison to 7.4 in the cytoplasm. This can trigger the release of loaded or attached molecules because the acidic $\mathrm{pH}$ in these vesicles is maintained by proton pumps; therefore, $\mathrm{pH}$-dependent release would be ideally suited for targeting viable cancer cells [72].

This $\mathrm{pH}$-sensitivity could be functionally exploited for delaying drug release from particles, which is particularly relevant in the bloodstream $(\mathrm{pH}=7.4)$. More detailed data on release of low molecular weight molecules ("Photosens") from vaterite microparticles was recently published [73]. The time course of release was determined starting from 5 min after immersion and was continued up to almost one week. In different experiments, the $\mathrm{pH}$ value of the ambient medium was varied, while Photosens was confined inside the carrier particles and was released during the transformation from vaterite to calcite particles, or amorphous calcium carbonate, except for residual amounts of the drug which reattached to the external surfaces. An interesting result here is the overall tendency of particles to dissolve quickly with decreasing $\mathrm{pH}$, thus leading to formation of calcite crystals, and/or amorphous $\mathrm{CaCO}_{3}$. This points to increasing solubility of calcium carbonate with decreasing $\mathrm{pH}$, in good agreement with the observed 3.7-fold relative difference in solubility between vaterite and calcite [74].

The time interval until complete dissolution of the vaterite crystals decreases significantly upon decrease of $\mathrm{pH}$. As such, the drug release is governed to a larger extent by the dissolution of the particles. At
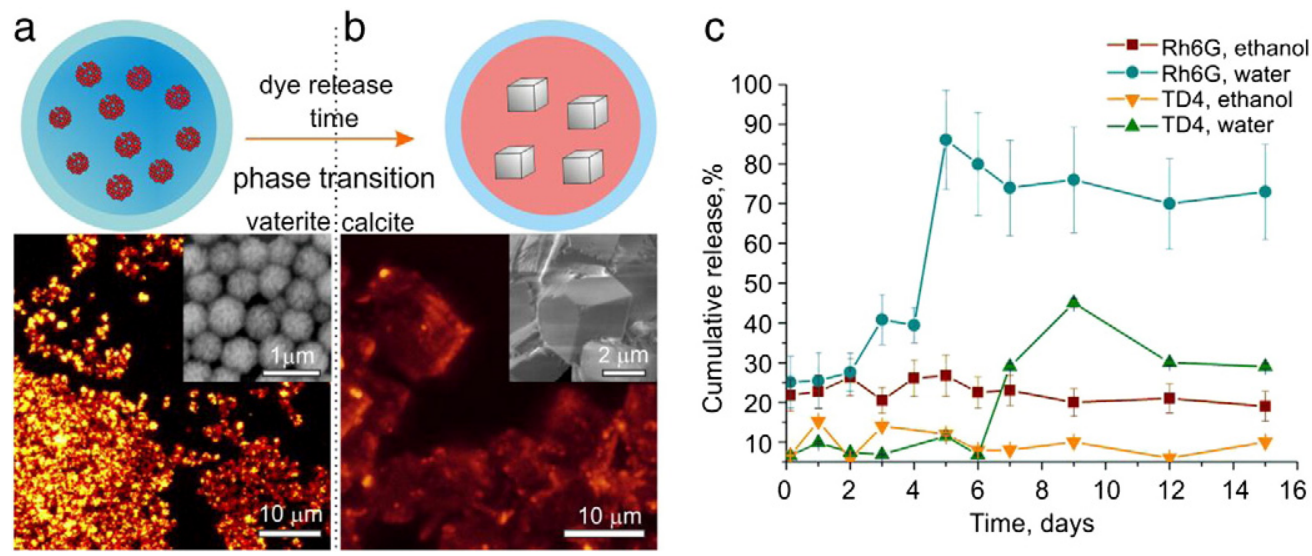

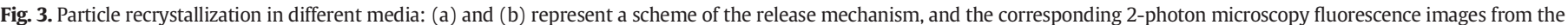

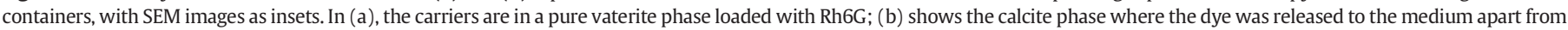

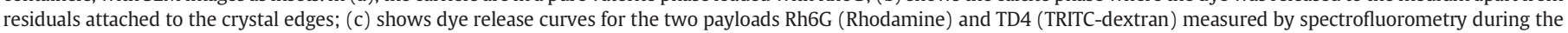
immersion in water and in ethanol. Reproduced from [52] with permission from The Royal Society of Chemistry. 
intermediate acidity in the range of $\mathrm{pH} 6.5$ to 5 , the dissolution times are shorter, and the vaterite particles dissolve completely already after one day. The shortest time of the phase transition was observed to take place at quite a low $\mathrm{pH}$ range ( 5 to 4.5 ), where both sizes of vaterite particles dissolved within the first five minutes. This led to immediate (burst) release of cargo from particles.

The above-described processes can be interpreted as follows: Drug release is first controlled by desorption. Complete release can then take place during the phase transition. In contrast to drug delivery applications performed in an open environment, a complete dispersion of the loaded compound can be expected after the dissolution of the vaterite particles. The differences between the time-dependent release curves of large and small particles are twofold: a) the time for reaching saturation increases from $\sim 1$ to $\sim 4$ days, and $b$ ) the saturation level is lower for larger particles because of their potential for an enhanced readsorption due to more efficient re-attachment to newly formed calcite structures $[55,66]$.

\subsection{Microparticles as carriers of enzymes}

Primarily, the role of particles has been considered here as templates for building polyelectrolyte multilayer capsules. However, the particles on which capsules are templated can also be used as carriers of enzymes. The polyelectrolyte multilayer shell can be constructed over such particles loaded with enzymes, providing an important functionality - protection of enzymes, just as in the case of capsules [75].

Capsules carrying enzymes in their pores have been prepared based on calcium carbonate matrix. Enzyme for the substrate can be added directly into a solution, although co-encapsulation of the substrate in liposomes, which are capable of carrying smaller molecules, has been shown applicable for initiating enzyme-catalyzed reactions. Peroxidase has been used in the above studies as the model system, while release of substrate from liposomes attached to the particles has been performed by ultrasound (Fig. 4).

Besides calcium carbonate particles serving as a reservoir for biomolecules, calcium phosphate cores are promising candidates for intracellular delivery of genetic material [76]. A number of studies have been devoted to the packaging of DNA, RNA, and oligonucleotides molecules in calcium phosphate nanoparticles [77]. The advantage of using calcium phosphate particles is that the size of these carriers can be adjusted on the ten-to-hundred nanometer scale which is important in cell transfection [78]. Furthermore, these carriers exert a protective role on the embedded material against the cellular environment, and allow for specific targeting functionalization of the calcium phosphate surface [79]. Designing artificial cells, initiating an enzyme-catalyzed reaction with protection of the enzyme from degradation in the surrounding medium, or drug delivery are some of the application areas of these approaches.

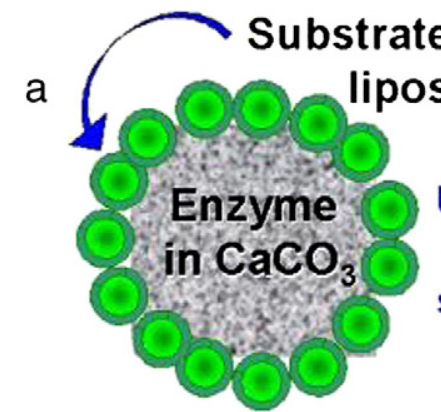

\section{in}
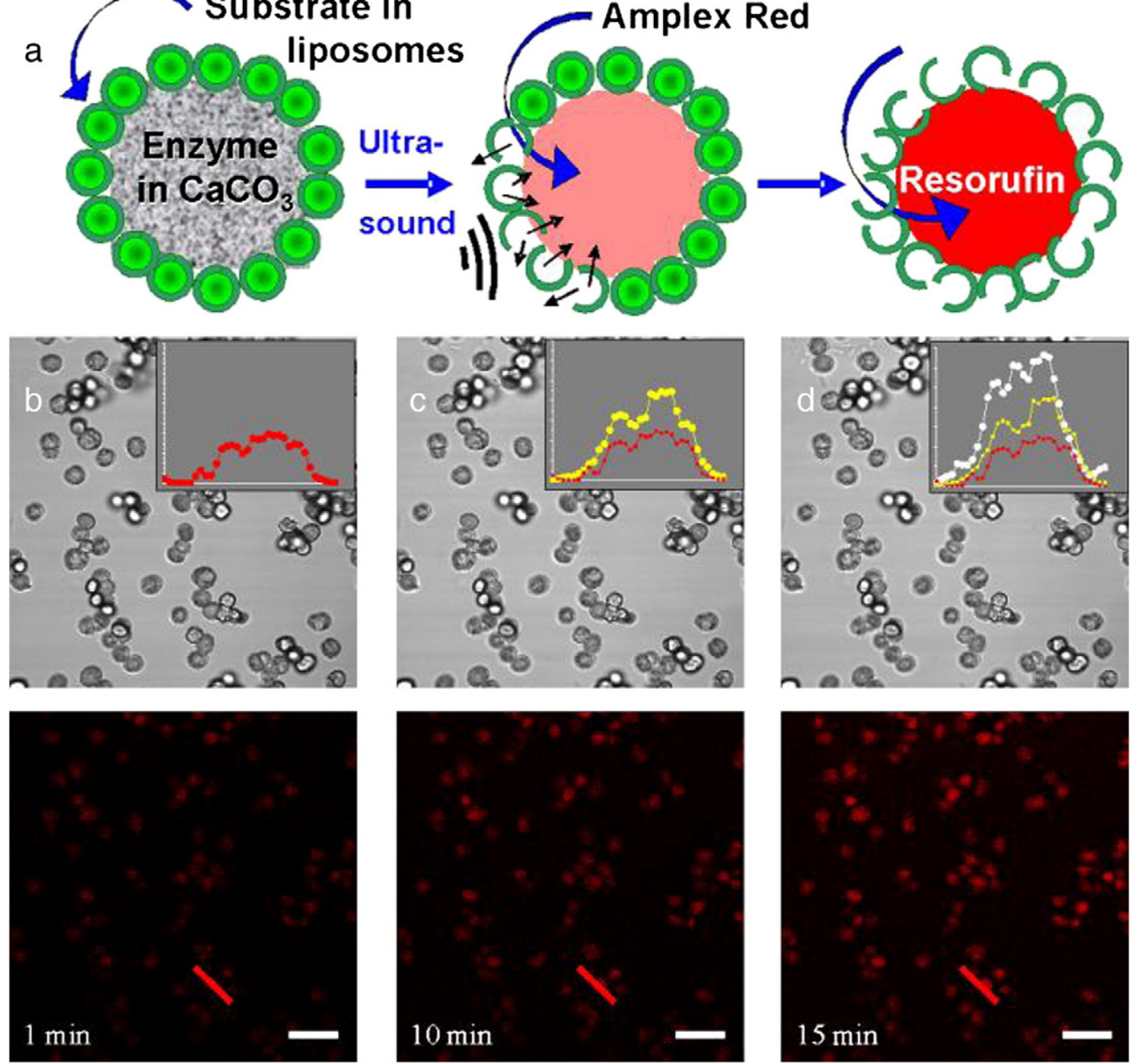

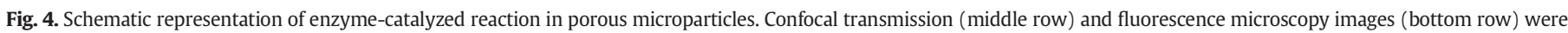
taken at the indicated time intervals. Figure reprinted from [75]. Copyright Wiley-VCH Verlag GmbH \& Co. KGaA. 


\subsection{Biomolecule-based particles}

Particles are also ideally suited to the delivery of some of the most relevant biomolecules. For example, insulin [80] or hemoglobin can be directly loaded into particles by calcium carbonate $[81,82]$ or manganese carbonate templating [83]. Such particles could also be suitable for biocompatible polymer coverage using the layer-by-layer (LbL) assembly approach. The advantage of microparticles of high deformability in combination with high loading capacity of hemoglobin, mimicking red blood cells [84], is the simplicity of manufacture as well as the fact that the particles themselves determine size and surface properties of the protein carriers.

\section{Capsules}

\subsection{From particles to capsules: dissolution of templates}

This overview covers the basics of capsule preparation and the role of particles in the properties inherited by capsules. Encapsulation efficiencies for capsules which are templated on either porous or smooth particles differ strongly. There are three basic methods of capsule formation (Fig. 5): i) co-precipitation whereby cargo molecules are loaded on the particles during their synthesis; ii) adsorption of cargo on pre-synthesized particles which are then used as template for the assembly of the polyelectrolyte shell; and iii) the loading of pre-formed hollow polyelectrolyte capsules.

Encapsulation during synthesis is widely used for molecules of high molecular weight, such as proteins. This method is based on the addition of cargo material to the salt solution reaction mixture with subsequent incorporation of the target molecules into the particle matrix. Porous particles like $\mathrm{CaCO}_{3}$ have been widely used for loading of molecules by this technique and exhibited a relatively high efficiency as compared to the adsorption method [85]. However, co-precipitation might decrease, or increase, the size of particles, change the surface morphology and the shape of the particles which could then be significantly different from particles produced in the absence of loaded molecules. Work of She et al., comparing encapsulation of molecules by both methods, i.e. co-precipitation and adsorption, demonstrated that loading efficiency of TRITC-BSA was higher in the co-precipitation approach [58]; we have recently obtained similar results for encapsulation of the therapeutic enzyme L-asparaginase [85]. The efficiency of adsorption of

\section{Porous particle}

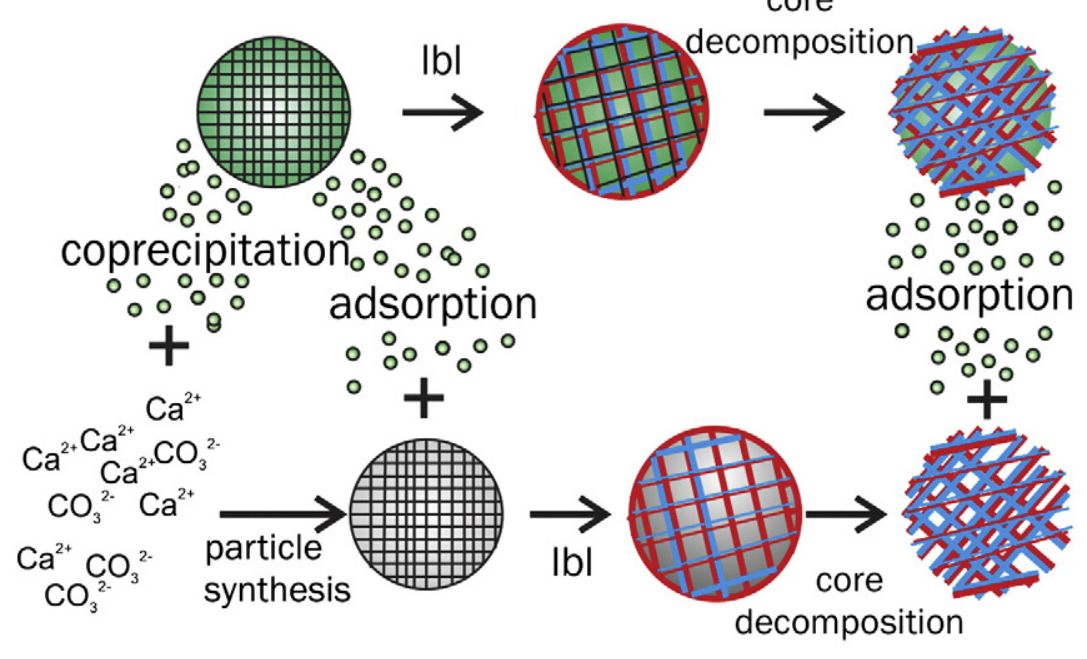

\section{Smooth particle}
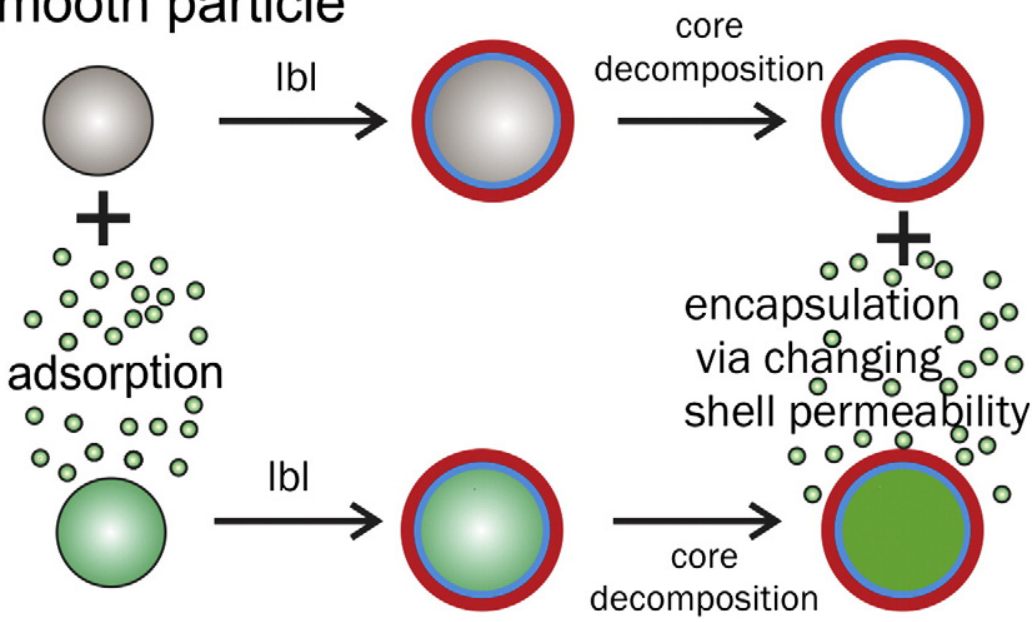

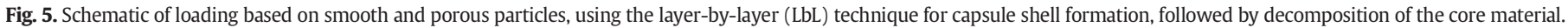


molecules on a porous matrix depends on the surface area and the size of pores: The higher the surface area and the larger the pore size, the higher the number of molecules contained within the particles. The surface charge is another parameter which determines the amount of molecules to be loaded into the particles. Two fluorescent markers were loaded into the vaterite containers: Rhodamine 6G (480 Da) and TRITC dextran, whereby the attachment of the dextran group increases the molecular weight by one order of magnitude to $4.4 \mathrm{kDa}$. In this way, the uptake of payload of different molecular properties could be quantitated: For the high molecular weight cargo, the loading efficiency was $157 \pm 24 \mu \mathrm{g} / \mathrm{mg}$, whereas for the low molecular weight substance Rhodamine 6G the loading efficiency depended on the number of washings. One to four repetitions resulted in efficiencies from $8 \pm 2 \mu \mathrm{g} / \mathrm{mg}$ to $(7 \pm 2) \cdot 10^{-2} \mu \mathrm{g} / \mathrm{mg}$. These efficiencies are of the same order as those of other substances loaded via adsorption to porous carriers [86-88]. Loading in pre-assembled capsules strongly depends on the type of cores used for the assembly of capsules. In the case of porous templates, the first polyelectrolyte layer determines the structure of the polymeric shell which is usually thick and appears as a polyelectrolyte network [31]. This polymeric matrix can be used for the loading of molecules by the adsorption technique, similar to the use of simple porous particles. In contrast to porous cores, the smooth ones display very different features because the polymers assembled onto the smooth surface form a thin polyelectrolyte shell that is only a few nanometers thick. The loading into polyelectrolyte capsules formed on smooth particles can be performed by changing physical parameters of environmental conditions. However, encapsulation methods based on variation of $\mathrm{pH}$, ionic strength, and solvent are not easy to implement, since for all of them a certain compound (acid/base, salt, organic solvent) has to be added to the capsule suspension, which can induce deformations through a transient osmotic shock.

The applicability of the three methods described in the previous section is restricted to certain compounds and/or capsule systems. Furthermore, the distribution of the large (above $4 \mathrm{kDa}$ ) entrapped molecules would be higher in the capsule wall than in their interior [89]. Of high importance for biomedical applications (e.g. laser-induced release) is the response to thermal shrinking of microcapsules functionalized with gold nanoparticles (AuNPs). Heating of (PDADMAC/PSS)n (where $\mathrm{n}$ is the number of layers) microcapsules has been shown to induce the reorganization of loosely arranged polyelectrolyte layers into a denser structure [90]. Thermally increasing the entropy incites more efficient, stronger electrostatic interactions between the oppositely charged layers (enthalpy increase), accompanied by densification of the polymeric shell and subsequent reduction of its inner volume. The shrinking behavior can be adjusted by the total number of bilayers, while its direction is predetermined by an odd (swelling) or even (shrinking) layer number due to the interplay of hydrophobic and electrostatic forces [91]. While denser microshells tend to be mechanically more stable, their permeability decreases with increasing bilayer number [92].

Modifications of the particle surface, or surface functionalization, are different for smooth and porous particles. The difference between polyelectrolyte capsules based on porous particles and non-porous ones regarding their optical properties was demonstrated in several works $[33,93,94]$. Polyelectrolyte capsules modified by gold $[33,93]$ or silver nanoparticles possessing plasmon resonance effects have been reported [94], revealing that the amount and distribution of metal nanoparticles in shells of polyelectrolyte capsules depend on the nature of the template. Capsules based on porous particles have better adsorption properties and exhibit higher surface-enhanced Raman spectroscopy (SERS) sensor effects [93]. If the number of nanoparticles used for adsorption also was controlled, capsules built on porous particles demonstrated that nanoparticles form larger elaborate aggregates [50,94,95] versus smaller aggregates on capsules with smooth surface $[5,96]$, which provide other interesting optical properties, such as control of absorption in the near-IR range [33,94].

\subsection{Release of cargo from capsules}

Release of payload molecules from microcapsules, which can be initiated by various stimuli ( $\mathrm{pH}$, ionic strength, solvent, and temperature), substantially depends on the morphology of the core. These stimuli have been shown to alter the permeability of capsule shells in a controllable and reversible way by creating tiny pores in the polymeric structure and thus facilitating diffusion of molecules. Such methods are broadly used for small-molecule drug delivery. However, application of chemical approaches might be limited in cellular systems where drastic changes in the chemical composition of the solution are not a viable option.

Fig. 6 presents data of a comparative study on release from microcapsules templated on either smooth silica particles (Fig. 6a,b), or on porous calcium carbonate particles (Fig. $6 c, d$ ). In the first case (Fig. 6c), thermally shrunk microcapsules have been used. These capsules can be functionalized with nanoplasmonic gold nanoparticles which serve as centers of localized temperature rise and permeability change. A distinctive feature of such capsules is the possibility of complete control over spatial and temporal release profiles. Alternatively, capsules templated on porous calcium carbonate are often used for release which is achieved through dissolution of the core material upon decomposition of the surrounding biodegradable polymers (Fig. 6d). We note that multifunctionality of release is yet another aspect which receives increasing attention [97]. In this regard, multi-functionality and multi-compartmentalization are essential properties [98,99].

\section{Complex morphologies of particles and capsules}

\subsection{Multi-compartment particles and capsules}

The multi-compartmentalization, which was mentioned in Section 2.4 and which represents a higher level of complexity, is a promising way to increase functionality of capsules destined for cargo transport into cells. Both particles and capsules can constitute multicompartmentalized carriers, whose main advantage is simultaneous delivery of different molecules, targeting $[100,101]$ using one carrier entity. The aforementioned encapsulation methods can also be adapted to the construction of a certain compartment of multi-compartment capsules: a) assembly from pre-formed different sub-compartments; b) synthesis of particles on which capsules are assembled; c) a combination of synthesis and assembly from pre-formed sub-compartments [102]. Of all multi-compartment capsules structures, the concentric and pericentric ones are most frequently used. Strategies for the construction of concentric capsules were demonstrated by Kreft and colleagues [103]. They demonstrated fabrication of the shell-in-shell capsules with two concentric calcium carbonate shells. These shells were independently loaded with biomolecules separated by a semipermeable polyelectrolyte membrane. Furthermore, this system has been tested as a reactor where the coupling of an enzymatic reaction through a semipermeable membrane was achieved via encapsulation of a substrate in one ball and an enzyme in the other one. Triggered release of the inner compartment of two-compartment capsules has been demonstrated [104]. The inner capsules were modified by metal nanoparticles, and upon near-infrared laser illumination the inner part of such dualcapsules was released. Three coupled enzymes were encapsulated into concentric multi-compartment $\mathrm{CaCO}_{3}$ particles via co-precipitation [105]. These enzymes were incorporated in separated compartments together with two spacing compartments made of bovine serum albumin (BSA). Strong influence of the spacing between compartments on the reaction kinetics was monitored through confocal laser scanning microscopy (CLSM). The cascade reaction catalyzed by enzymes introduced in separate polymersomes, without artificial transport mediator located in the membrane, has been demonstrated by Kuiper et al. [106].

Pericentric microcapsules are another example of multi-compartment carriers. This type of complex capsules can be constructed by 


\section{Synthetic capsules, triggered release}
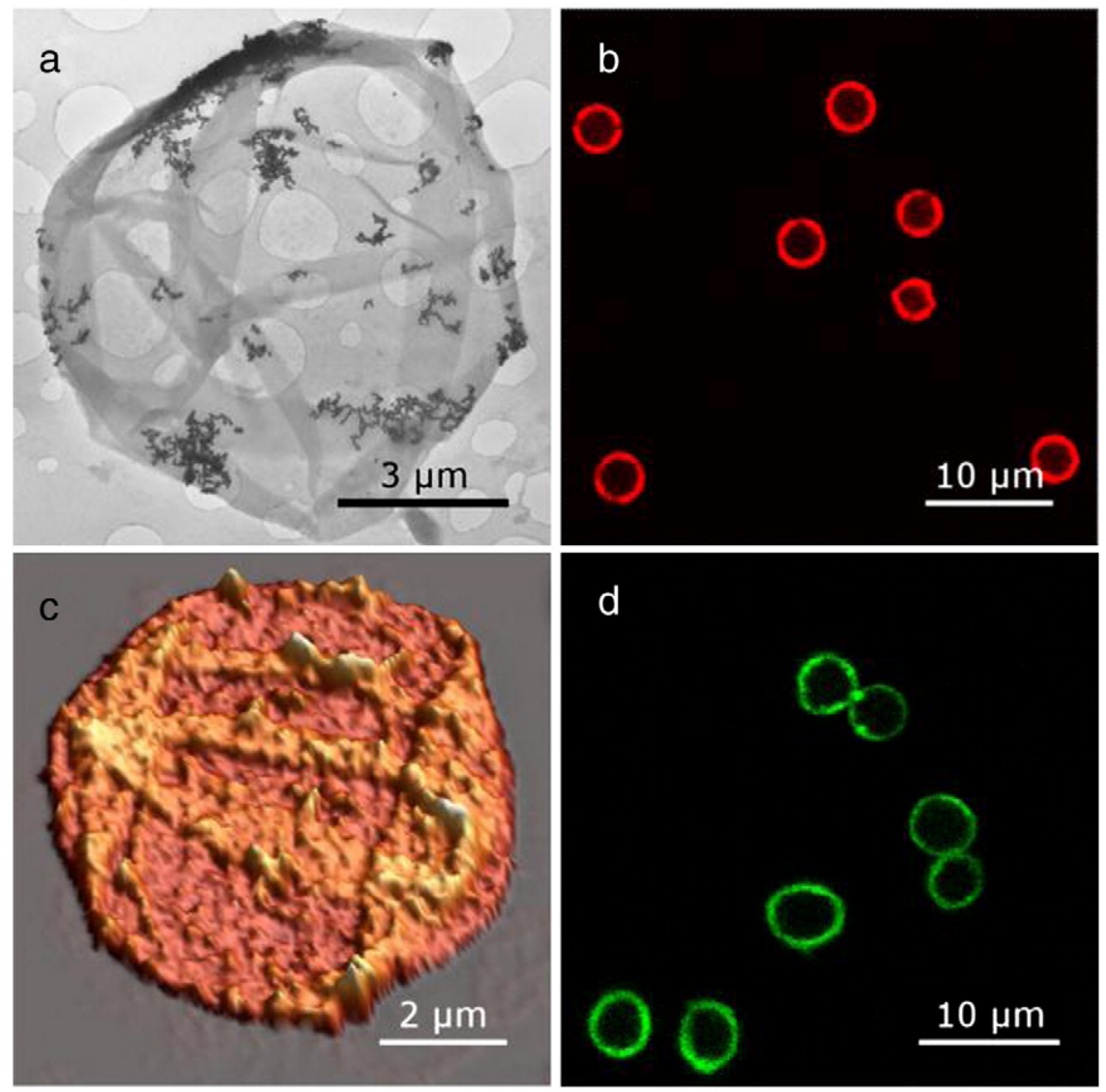

Biodegradable capsules, gradual release

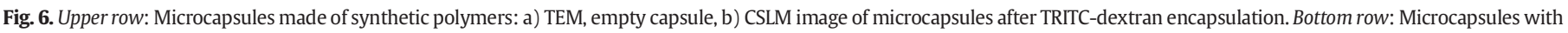

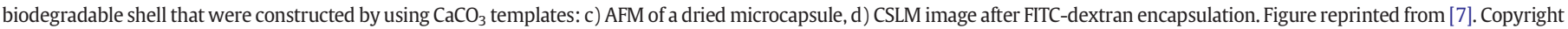
Wiley-VCH Verlag GmbH \& Co. KGaA.

surrounding a large container with small ones. One approach to manufacture pericentric capsules is to use polyelectrolyte-coated particles modified via electrostatic attraction between small and large counterparts [86]. Porous colloids, such as calcium carbonate cores, can also be applied for assembly of pericentric compartments due, in a large part, to their large surface-to-volume ratio and plenty of cavities $[74,80]$. By using pericentric structures made of calcium carbonate as inner core, filled with an enzyme surrounded by liposomes containing a substrate, an enzyme-catalyzed reaction was performed [74]. By disrupting liposomes via ultrasonication, the course of the reaction in large particle volumes was observed by CLSM. Detachment of small containers from the inner particles has been demonstrated to permit control of the release of small carriers via biodegradation of polyelectrolytes upon enzymatic disruption [80]. An overview of various morphologies of multi-compartment particles and capsules has been recently presented [107], while different ways of inwards build-up of concentric polymeric (polyamines and polyacids layers) capsules templated on agarose or alginate hydrogels in an organic phase [108] have been shown. Generation of hybrid liposome-polymersome multicompartment assemblies [109] has been also demonstrated.

\subsection{Anisotropic capsules and anisotropic carriers}

Of all parameters pertaining to particles as drug delivery vehicles, the shape has been shown to be a valuable characteristic which influences the internalization and further fate of the particles in the cell. Recent findings suggest that the geometry of particles could change their efficiency of uptake into cells in the phagocytotic process [110]. The carrier geometry of polymer particles was found to influence endothelial targeting in the vasculature, and the rate of endocytosis and lysosomal transport within endothelial cells [111]. Specifically, non-spherical (elongated, rod-like) particles revealed higher intracellular transport as compared to that of spherical carriers $[112,113]$. Attachment of particles to specific sites of cells can be tuned not only via surface chemistry of vehicles, but also by changing the geometry of particles even at the nanoscale [114-116]. Thus, future trends in particle-directed drug delivery are toward novel methods of synthesis and elaboration of anisotropic particles which in specific cases resemble natural vehicles like bacteria [117]. Not only particles of certain shapes can be used as delivery system, but also capsules templated on specifically shaped particles would be beneficial to certain applications $[118,119]$. The flexibility of polyelectrolytes molecules allows reproducing a number of capsule shapes after decomposition of the initial solid cores [119-121]. Shchepelina et al. compared the morphology, mechanical properties, and permeability of hydrogen-bonded layer-by-layer (LbL) microcapsule shells assembled on squared cadmium carbonate particles against the same shells assembled on spherical silica. [122] The patterned template-assisted assembly of the cubic micro-particles driven by the competing capillary, Coulomb, and van der Waals forces was compared to the traditional spherical colloidal microparticles that had been studied by Lisunova et al. [123]. A set of shaped (spherical, elliptical, and squared) $\mathrm{CaCO}_{3}$ particles was synthesized through changing the stirring speed, time, $\mathrm{pH}$ value, and salt ratio (Fig. 7). The particles were further used for building polyelectrolyte capsules loaded with labeled dextran 

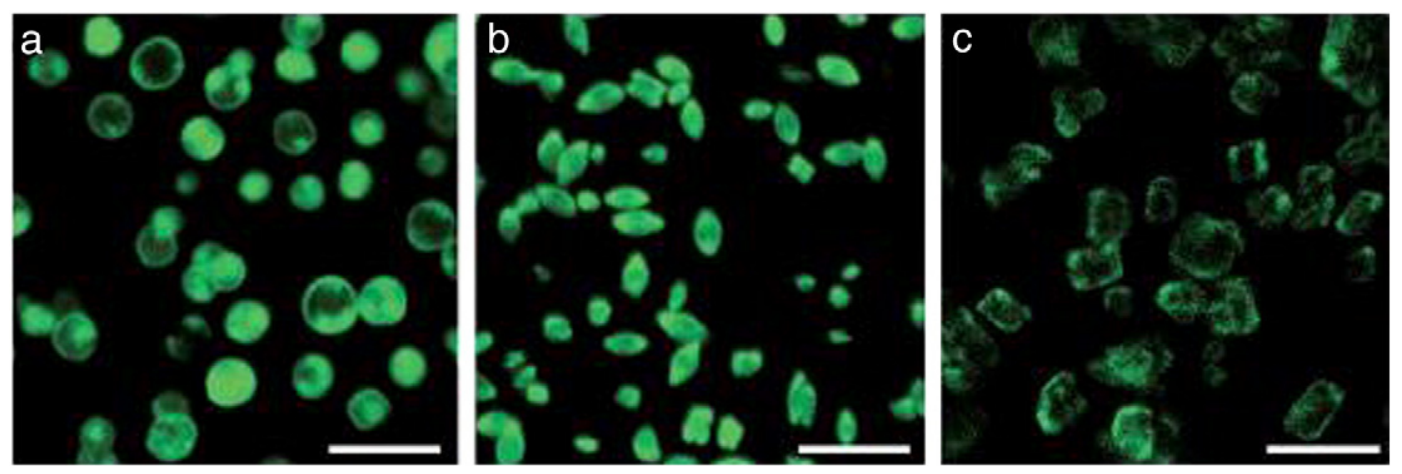

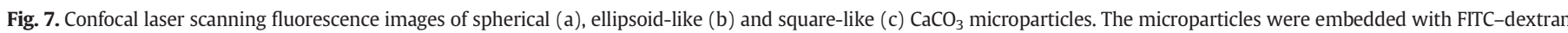

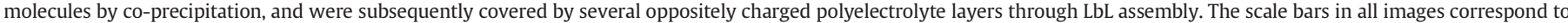
$5 \mu \mathrm{m}$. Adapted from [22] with permission from The Royal Society of Chemistry.

molecules which replicate the initial shape of $\mathrm{CaCO}_{3}$ microcores after decomposition with EDTA [22].

Another promising concept for manufacturing anisotropic carriers is multi-compartmentalization under conditions where at least two particles/capsules interact with each other $[98,107,124,125]$. Such anisotropic hierarchy of nano- and microparticles/capsules makes it possible to generate properties of carriers that could not be achieved using conventional methods. Bio-inspired reactions occurring in the confined volume of particles/capsules have been carried out by applying multi-compartment approaches [107,117,125,126]. Advantages of the artificial compartmentalization strategy are the separation of large and small molecules, while at the same time carrying them in one entity with protection from the outside environment, and conduction of cascade reactions [127]. Furthermore, multi-compartment particles/capsules are predicted to be of potential use in theranostic applications where one carrier would perform a dual function: diagnostic and therapeutic $[128,129]$. Direct synthesis of anisotropic particles can be another approach to anisotropic carriers [130], while controlled patchiness [131] provides another advanced functionality. In addition to particles described above, some exotic templates include also bacteria [132], microcrystals [133], and worms [134].

\section{Summary}

In this overview, we highlighted methods of preparation and major physico-chemical properties of particles used as delivery carriers and particles serving as templates (cores) on which polyelectrolyte multilayer capsules are assembled. With regard to capsules, the choice of the template material determines, first and foremost, its physicochemical and biological properties. Porous particles are presented, as well as those possessing smooth surface. Non-particle, hybrid composites (red blood cells, virus-like particles, and liposomes) are also briefly discussed. It is important to emphasize that properties of microcapsules, which are built on such templates, substantially depend on the templates on which the former are assembled, as also overviewed here. Finally, reference is made to emerging trends in the development of particles and capsules, the production of multicompartment and anisotropic particles, and particles of controlled size, porosity, and monodispersity.

\section{References}

[1] Yu A, Wang Y, Barlow E, Caruso F. Mesoporous silica particles as templates for preparing enzyme-loaded biocompatible microcapsules. Adv Mater 2005;17:1737-41.

[2] Sivakumar S, Bansal V, Cortez C, Chong S-F, Zelikin AN, Caruso F. Degradable, surfactant-free, monodisperse polymer-encapsulated emulsions as anticancer drug carriers. Adv Mater 2009;21:1820-4.

[3] Hartmann L, Bedard M, Börner HG, Möhwald H, Sukhorukov GB, Antonietti M. $\mathrm{CO}_{2}$ switchable oligoamine patches based on amino acids and their use to build polyelectrolyte containers with intelligent gating. Soft Matter 2008;4:534-9.
[4] Studer D, Palankar R, Bédard MF, Winterhalter M, Springer S. Retrieval of a metabolite from cells with polyelectrolyte microcapsules. Small 2010;6:2412-9.

[5] Parakhonskiy BV, Bedard M, Bukreeva T, Sukhorukov GB, Möhwald H, Skirtach AG. Nanoparticles on polyelectrolytes at low concentration: controlling concentration and size. J Phys Chem C 2010;114:1996-2002.

[6] Muñoz-Javier A, del Pino P, Bedard M, Ho D, Skirtach AG, Sukhorukov GB, et al. Photoactivated release of cargo from the cavity of polyelectrolyte capsules to the cytosol of cells. Langmuir 2008;24:12517-20.

[7] Pavlov AM, Sapelkin AV, Huang X, P'ng KMY, Bushby AJ, Sukhorukov GB, et al. Neuron cells uptake of polymeric microcapsules and subsequent intracellular release. Macromol Biosci 2011;11:848-54.

[8] Khopade AJ, Caruso F. Two-component, ultrathin microcapsules prepared by a core-mediated layer-by-layer approach. Chem Mater 2004;16:2107-12.

[9] Vinogradova OI, Andrienko D, Lulevich VV, Nordschild S, Sukhorukov GB. Young's modulus of polyelectrolyte multilayers from microcapsule swelling. Macromolecules 2004;37:1113-7.

[10] Lulevich VV, Andrienko D, Vinogradova OI. Elasticity of polyelectrolyte multilayer microcapsules. J Chem Phys 2004;120:3822-6.

[11] Gao C, Moya SE, Lichtenfeld H, Casoli A, Fiedler H, Donath E, et al. The decomposition process of melamine formaldehyde cores: the key step in the fabrication of ultrathin polyelectrolyte multilayer capsules. Macromol Mater Eng 2001;286:355-61.

[12] Peyratout CS, Dähne L. Tailor-made polyelectrolyte microcapsules: from multilayers to smart containers. Angew Chem Int Ed Engl 2004;43:3762-83.

[13] Sukhorukov GB, Shchukin DG, Dong W-F, Möhwald H, Lulevich VV, Vinogradova OI. Comparative analysis of hollow and filled polyelectrolyte microcapsules templated on melamine formaldehyde and carbonate cores. Macromol Chem Phys 2004;205:530-5.

[14] Skirtach AG, De Geest BG, Mamedov AA, Antipov AA, Kotov NA, Sukhorukov GB. Ultrasound stimulated release and catalysis using polyelectrolyte multilayer capsules. J Mater Chem 2007; 17:1050-4.

[15] Radtchenko IL, Giersig M, Sukhorukov GB. Inorganic particle synthesis in confined micron-sized polyelectrolyte capsules. Langmuir 2002;18:8204-8.

[16] Lulevich VV, Radtchenko IL, Sukhorukov GB, Vinogradova OI. Deformation properties of nonadhesive polyelectrolyte microcapsules studied with the atomic force microscope. J Phys Chem B 2003;107:2735-40.

[17] Bédard MF, Skirtach AG, Sukhorukov GB. Optically driven encapsulation using novel polymeric hollow shells containing an azobenzene polymer. Macromol Rapid Commun 2007;28:1517-21.

[18] Bukreeva T, Marchenko IV, Parakhonskiy BV, Grigor'ev YV. Formation of silver nanoparticles on shells of polyelectrolyte capsules using silver-mirror reaction. Colloid J 2009;71:596-602.

[19] Shchukin DG, Gorin DA, Möhwald H. Ultrasonically induced opening of polyelectrolyte microcontainers. Langmuir 2006;22:7400-4.

[20] Dubreuil F, Elsner N, Fery A. Elastic properties of polyelectrolyte capsules studied by atomic-force microscopy and RICM. Eur Phys J E Soft Matter 2003;12:215-21.

[21] Silvano D, Krol S, Diaspro A, Cavalleri O, Gliozzi A. Confocal laser scanning microscopy to study formation and properties of polyelectrolyte nanocapsules derived from $\mathrm{CdCO}_{3}$ templates. Microsc Res Tech 2002;59:536-41.

[22] Yashchenok AM, Parakhonskiy BV, Donatan S, Kohler D, Skirtach AG, Möhwald H. Polyelectrolyte multilayer microcapsules templated on spherical, elliptical and square calcium carbonate particles. J Mater Chem B 2013;1:1223-8.

[23] Schwiertz J, Meyer-Zaika W, Ruiz-Gonzalez L, González-Calbet JM, Vallet-Regí M, Epple M. Calcium phosphate nanoparticles as templates for nanocapsules prepared by the layer-by-layer technique. J Mater Chem 2008;18:3831-4.

[24] Schneider G, Decher G. From functional core/shell nanoparticles prepared via layerby-layer deposition to empty nanospheres. Nano Lett 2004;4:1833-9.

[25] Bédard MF, De Geest BG, Möhwald H, Sukhorukov GB, Skirtach AG. Direction specific release from giant microgel-templated polyelectrolyte microcontainers. Soft Matter 2009;5:3927-31.

[26] Zhu H, Srivastava R, Brown JQ McShane MJ. Combined physical and chemical immobilization of glucose oxidase in alginate microspheres improves stability of encapsulation and activity. Bioconjug Chem 2005;16:1451-8. 
[27] Abdullaev E, Shchukin D, Lvov Y. Halloysite Clay Nanotubes as a Reservoir for Corrosion Inhibitors and Template for Layer-by-Layer Encapsulation. Polymer Mater Sci Eng 2008;99:121-2.

[28] Wang Y, Yan Y, Cui J, Hosta-Rigau L, Heath JK, Nice EC, et al. Encapsulation of waterinsoluble drugs in polymer capsules prepared using mesoporous silica templates for intracellular drug delivery. Adv Mater 2010;22:4293-7.

[29] Wang Y, Yu A, Caruso F. Nanoporous polyelectrolyte spheres prepared by sequentially coating sacrificial mesoporous silica spheres. Angew Chem Int Ed Engl 2005;44:2888-92.

[30] Borodina TN, Rumsh LD, Kunizhev SM, Sukhorukov GB, Vorozhtsov GN, Feldman BM, et al. Polyelectrolyte microcapsules as the systems. Biochemistry 2008;2:88-93.

[31] Volodkin DV, Petrov AI, Prevot M, Sukhorukov GB. Matrix polyelectrolyte microcapsules: new system for macromolecule encapsulation. Langmuir 2004;20:3398-406.

[32] Déjugnat C, Sukhorukov GB. pH-responsive properties of hollow polyelectrolyte microcapsules templated on various cores. Langmuir 2004;20:7265-9.

[33] Bukreeva T, Parakhonskiy BV, Skirtach AG, Susha AS, Sukhorukov GB. Preparation of polyelectrolyte microcapsules with silver and gold nanoparticles in a shell and the remote destruction of microcapsules under laser irradiation. Crystallogr Rep 2006;51:863-9.

[34] Shchukin DG, Sukhorukov GB. Selective $\mathrm{YF}_{3}$ nanoparticle formation in polyelectrolyte capsules as microcontainers for yttrium recovery from aqueous solutions. Langmuir 2003;19:4427-31.

[35] De Geest BG, Déjugnat C, Prevot M, Sukhorukov GB, Demeester J, De Smedt SC. Selfrupturing and hollow microcapsules prepared from bio-polyelectrolyte-coated microgels. Adv Funct Mater 2007:17:531-7.

[36] Lu Z, Prouty MD, Guo Z, Golub VO, Kumar CSSR, Lvov YM. Magnetic switch of permeability for polyelectrolyte microcapsules embedded with Co@Au nanoparticles. Langmuir 2005;21:2042-50.

[37] Donath E, Moya SE, Neu B, Sukhorukov GB, Georgieva R, Voigt A, et al. Hollow polymer shells from biological templates: fabrication and potential applications. Chem Eur J 2002;8:5481-5.

[38] Georgieva R, Moya SE, Hin M, Mitlöhner R, Donath E, Kiesewetter H, et al. Permeation of macromolecules into polyelectrolyte microcapsules. Biomacromolecules 2002;3:517-24.

[39] Kreft O, Georgieva R, Bäumler H, Steup M, Müller-Röber B, Sukhorukov GB, et al. Red blood cell templated polyelectrolyte capsules: a novel vehicle for the stable encapsulation of DNA and proteins. Macromol Rapid Commun 2006;27:435-40.

[40] Moya SE. Polyelectrolyte multilayer capsules templated on biological cells: core oxidation influences layer chemistry. Colloids Surf A 2001;183-185:27-40.

[41] Diaspro A, Silvano D, Krol S, Cavalleri O, Gliozzi A. Single living cell encapsulation in nano-organized polyelectrolyte shells. Langmuir 2002;18:5047-50.

[42] Neu B, Voigt A, Mitlöhner R, Leporatti S, Gao CY, Donath E, et al. Biological cells as templates for hollow microcapsules. J Microencapsul 2007;18:385-95.

[43] Fischlechner M, Zschörnig O, Hofmann J, Donath E. Engineering virus functionalities on colloidal polyelectrolyte lipid composites. Angew Chem 2005; $117: 2952-5$.

[44] Cuomo F, Lopez F, Ceglie A, Maiuro L, Miguel MG, Lindman B. pH-responsive liposome-templated polyelectrolyte nanocapsules. Soft Matter 2012:8:4415-20.

[45] Habraken WJEM, Tao J, Brylka LJ, Friedrich H, Bertinetti L, Schenk AS, et al. Ionassociation complexes unite classical and non-classical theories for the biomimetic nucleation of calcium phosphate. Nat Commun 2013;4:1507.

[46] Cai Y, Liu Y, Yan W, Hu Q, Tao J, Zhang M, et al. Role of hydroxyapatite nanoparticle size in bone cell proliferation. J Mater Chem 2007; 17:3780-7.

[47] Andreassen J-P. Formation mechanism and morphology in precipitation of vaterite-nano-aggregation or crystal growth? J Cryst Growth 2005;274:256-64

[48] Brecević L, Nielsen AE. Solubility of amorphous calcium carbonate. J Cryst Growth 1989;98:504-10.

[49] Schmidt S, Volodkin DV. Microparticulate biomolecules by mild $\mathrm{CaCO}_{3}$ templating. J Mater Chem B 2013;1:1210-8.

[50] Parakhonskiy BV, Haase A, Antolini R. Sub-micrometer vaterite containers: synthesis, substance loading, and release. Angew Chem Int Ed Engl 2012;51:1195-7.

[51] Behra M, Schmidt S, Hartmann J, Volodkin DV, Hartmann L. Synthesis of porous PEG microgels using CaCO3 microspheres as hard templates. Macromol Rapid Commun 2012;33:1049-54.

[52] Parakhonskiy BV, Foss C, Carletti E, Fedel M, Haase A, Motta A, et al. Tailored intracellular delivery via a crystal phase transition in $400 \mathrm{~nm}$ vaterite particles. Biomater Sci 2013;1:1273-81.

[53] Janeković A, Matijević E. Preparation of monodispersed colloidal cadmium compounds. J Colloid Interface Sci 1985; 103:436-47.

[54] Schulz-Ekloff G. Mesoporous silica with controlled porous structure and regular morphology. Int J Inorg Mater 1999;1:97-102.

[55] Svenskaya Y, Parakhonskiy BV, Haase A, Atkin V, Lukyanets E, Gorin DA, et al. Anticancer drug delivery system based on calcium carbonate particles loaded with a photosensitizer. Biophys Chem 2013;182:11-5

[56] Reibetanz U, Schönberg M, Rathmann S, Strehlow V, Göse M, Lessig J. Inhibition of human neutrophil elastase by $\alpha 1$-antitrypsin functionalized colloidal microcarriers. ACS Nano 2012;6:6325-36.

[57] Washington C. Drug release from microdisperse systems: a critical review. Int J Pharm 1990;58:1-12.

[58] She Z, Antipina MN, Li J, Sukhorukov GB. Mechanism of protein release from polyelectrolyte multilayer microcapsules. Biomacromolecules 2010;11:1241-7.

[59] Peng C, Zhao Q, Gao C. Sustained delivery of doxorubicin by porous $\mathrm{CaCO}_{3}$ and chitosan/alginate multilayers-coated $\mathrm{CaCO}_{3}$ microparticles. Colloids Surf A 2010;353:132-9.
[60] Park J-H, Gu L, von Maltzahn G, Ruoslahti E, Bhatia SN, Sailor MJ. Biodegradable luminescent porous silicon nanoparticles for in vivo applications. Nat Mater 2009;8:331-6.

[61] Li Z-Z, Wen L-X, Shao L, Chen J-F. Fabrication of porous hollow silica nanoparticles and their applications in drug release control. J Control Release 2004;98:245-54

[62] Barbe C, Bartlett J, Kong L, Finnie K, Lin HQ Larkin M, et al. Silica particles: a novel drug-delivery system. Adv Mater 2004:16:1959-66.

[63] Xue JM, Shi M. PLGA/mesoporous silica hybrid structure for controlled drug release. J Control Release 2004;98:209-17.

[64] Panyam J, Labhasetwar V. Biodegradable nanoparticles for drug and gene delivery to cells and tissue. Adv Drug Deliv Rev 2003;55:329-47.

[65] Desai MP, Labhasetwar V, Amidon GL, Levy RJ. Gastrointestinal uptake of biodegradable microparticles: effect of particle size. Pharm Res 1996; $13: 1838-45$

[66] Parakhonskiy BV, Tessarolo F, Haase A, Antolini R. Dependence of sub-micron vaterite container release properties on $\mathrm{pH}$ and ionic strength of the surrounding solution. Adv Sci Technol 2012;86:81-5.

[67] Spanos N, Koutsoukos PG. The transformation of vaterite to calcite: effect of the conditions of the solutions in contact with the mineral phase. J Cryst Growth 1998;191:783-90.

68] Eriksson R, Merta J, Rosenholm JB. The calcite/water interface I. Surface charge in indifferent electrolyte media and the influence of low-molecular-weight polyelectrolyte. J Colloid Interface Sci 2007;313:184-93.

[69] Eriksson R, Merta J, Rosenholm JB. The calcite/water interface II. Effect of added lattice ions on the charge properties and adsorption of sodium polyacrylate. J Colloid Interface Sci 2008;326:396-402.

[70] Volodkin DV, von Klitzing R, Möhwald H. Pure protein microspheres by calcium carbonate templating. Angew Chem Int Ed Engl 2010;49:9258-61.

[71] Tannock I, Rotin D. Acid pH in tumors and its potential for therapeutic exploitation. Cancer Res 1989:4373-84.

[72] Urano Y, Asanuma D, Hama Y, Koyama Y, Barrett T, Kamiya M, et al. Selective molecular imaging of viable cancer cells with $\mathrm{pH}$-activatable fluorescence probes. Nat Med 2009;15:104-9.

[73] Svenskaya Y, Parakhonskiy B, Haase A, Atkin V, Lukyanets E, Gorin D, et al. Anticancer drug delivery system based on calcium carbonate particles loaded with a photosensitizer. Biophys Chem 2013;182:11-5.

[74] Xu A-W, Dong W-F, Antonietti M, Cölfen H. Polymorph switching of calcium carbonate crystals by polymer-controlled crystallization. Adv Funct Mater 2008;18:1307-13.

[75] Yashchenok AM, Delcea M, Videnova K, Jares-Erijman EA, Jovin TM, Konrad M, et al. Enzyme reaction in the pores of $\mathrm{CaCO}_{3}$ particles upon ultrasound disruption of attached substrate-filled liposomes. Angew Chem Int Ed Engl 2010;49:8116-20

[76] Welzel T, Radtke I, Meyer-Zaika W, Heumann R, Epple M. Transfection of cells with custom-made calcium phosphate nanoparticles coated with DNA. J Mater Chem 2004; $14: 2213-7$

[77] Sokolova V, Kovtun A, Prymak O, Meyer-Zaika W, Kubareva EA, Romanova EA, et al. Functionalisation of calcium phosphate nanoparticles by oligonucleotides and their application for gene silencing. J Mater Chem 2007;17:721-7.

[78] Sokolova V, Rotan O, Klesing J, Nalbant P, Buer J, Knuschke T, et al. Calcium phosphate nanoparticles as versatile carrier for small and large molecules across cell membranes. J Nanoparticle Res 2012;14:910.

[79] Sokolova V, Knuschke T, Buer J, Westendorf AM, Epple M. Quantitative determination of the composition of multi-shell calcium phosphate-oligonucleotide nanoparticles and their application for the activation of dendritic cells. Acta Biomater 2011:7:4029-36

[80] Volodkin DV, Schmidt S, Fernandes P, Larionova NI, Sukhorukov GB, Duschl C, et al. One-step formulation of protein microparticles with tailored properties: hard templating at soft conditions. Adv Funct Mater 2012;22:1914-22.

[81] Nicolas J, Bensaid F, Desmaële D, Grogna M, Detrembleur C, Andrieux K, et al. Synthesis of highly functionalized poly(alkyl cyanoacrylate) nanoparticles by means of click chemistry. Macromolecules 2008;41:8418-28.

[82] Duan L, Yan X, Wang A, Jia Y, Li J. Highly loaded hemoglobin spheres as promising artificial oxygen carriers. ACS Nano 2012;6:6897-904.

[83] Xiong Y, Liu ZZ, Georgieva R, Smuda K, Steffen A, Sendeski M, et al. Nonvasoconstrictive hemoglobin particles as oxygen carriers. ACS Nano 2013;7:7454-61.

[84] Chen K, Merkel TJ, Pandya A, Napier ME, Luft JC, Daniel W, et al. Low modulus biomimetic microgel particles with high loading of hemoglobin. Biomacromolecules 2012:13:2748-59.

[85] Karamitros CS, Yashchenok AM, Möhwald H, Skirtach AG, Konrad M. Preserving catalytic activity and enhancing biochemical stability of the therapeutic enzyme asparaginase by biocompatible multilayered polyelectrolyte microcapsules. Biomacromolecules 2013:14:4398-406.

[86] Soppimath KS, Aminabhavi TM, Kulkarni AR, Rudzinski WE. Biodegradable polymeric nanoparticles as drug delivery devices. J Control Release 2001;70:1-20.

[87] Fujiwara M, Shiokawa K, Kubota T. Direct encapsulation of proteins into calcium silicate microparticles by water/oil/water interfacial reaction method and their responsive release behaviors. Mater Sci Eng C 2012;32:2484-90.

[88] Mondon K, Zeisser-Labouèbe M, Gurny R, Möller M. MPEG-hexPLA micelles as novel carriers for hypericin, a fluorescent marker for use in cancer diagnostics. Photochem Photobiol 2011;87:399-407.

[89] Volodkin DV, Larionova NI, Sukhorukov GB. Protein encapsulation via porous CaCO3 microparticles templating. Biomacromolecules 2004;5:1962-72. 
[90] Déjugnat C, Köhler K, Dubois M, Sukhorukov GB, Möhwald H, Zemb T, et al. Membrane densification of heated polyelectrolyte multilayer capsules characterized by soft X-ray microscopy. Adv Mater 2007;19:1331-6.

[91] Köhler K, Shchukin DG, Möhwald H, Sukhorukov GB. Thermal behavior of polyelectrolyte multilayer microcapsules. 1 . The effect of odd and even layer number. J Phys Chem B 2005;109:18250-9.

[92] Marchenko I, Yashchenok AM, Borodina TN, Bukreeva T, Konrad M, Möhwald $\mathrm{H}$, et al. Controlled enzyme-catalyzed degradation of polymeric capsules templated on $\mathrm{CaCO}$ : influence of the number of LbL layers, conditions of degradation, and disassembly of multicompartments. J Control Release 2012;162:599-605.

[93] Yashchenok AM, Borisova D, Parakhonskiy BV, Masic A, Pinchasik B-E, Möhwald H, et al. Nanoplasmonic smooth silica versus porous calcium carbonate bead biosensors for detection of biomarkers. Ann Phys 2012;524:723-32.

[94] Bukreeva TV, Parakhonskiy BV, Marchenko IV, Khlebtsov BN, Khlebtsov NG, Dementieva OV, et al. Polyelectrolyte microcapsules with a shell containing silver and gold nanoparticles, based on calcium carbonate and polystyrene cores. Nanotechnol Russ 2008;3:85-93.

[95] Parakhonskiy BV, Bukreeva T, Parakhonskiy GV, Skirtach AG, Sukhorukov GB Khlebtsov NG, et al. Permeability adjustment of polyelectrolyte micro- and nanocapsules by laser irradiation. In: Zimnyakov DA, Khlebtsov NG, editors. Proc. SPIE, SPIE; 2007 [pp. 653605-653605-8].

[96] Skirtach AG, Dejugnat C, Braun D, Susha AS, Rogach AL, Parak WJ, et al. The role of metal nanoparticles in remote release of encapsulated materials. Nano Lett 2005;5:1371-7.

[97] Yi Q, Sukhorukov GB. Externally triggered dual function of complex microcapsules. ACS Nano 2013;7:8693-705.

[98] Chandrawati R, van Koeverden MP, Lomas H, Caruso F. Multicompartment particle assemblies for bioinspired encapsulated reactions. J Phys Chem Lett 2011;2:2639-49.

[99] Costa RR, Castro E, Arias FJ, Rodríguez-Cabello JC, Mano JF. Multifunctional compartmentalized capsules with a hierarchical organization from the nano to the macro scales. Biomacromolecules 2013:14:2403-10.

[100] Cortez C, Tomaskovic-Crook E, Johnston APR, Radt B, Cody SH, Scott AM, et al. Targeting and uptake of multilayered particles to colorectal cancer cells. Adv Mater 2006;18:1998-2003.

[101] Vergaro V, Baldassarre F, De Santis F, Ciccarella G, Giannelli G, Leporatti S. TGF-beta Inihibitor-loaded polyelectrolyte multilayers capsules for sustained targeting of hepatocarcinoma cells. Curr Pharm Des 2012;18:4155-64.

[102] Sandre O, Moreaux L, Brochard-Wyart F. Dynamics of transient pores in stretched vesicles. Proc Natl Acad Sci U S A 1999;96:10591-6.

[103] Kreft O, Prevot M, Möhwald H, Sukhorukov GB. Shell-in-shell microcapsules: a novel tool for integrated, spatially confined enzymatic reactions. Angew Chem Int Ed Engl 2007;46:5605-8.

[104] Kreft O, Skirtach AG, Sukhorukov GB, Möhwald H. Remote control of bioreactions in multicompartment capsules. Adv Mater 2007;19:3142-5

[105] Bäumler H, Georgieva R. Coupled enzyme reactions in multicompartment microparticles. Biomacromolecules 2010;11:1480-7.

[106] Kuiper SM, Nallani M, Vriezema DM, Cornelissen JJLM, van Hest JCM, Nolte RJM, et al. Enzymes containing porous polymersomes as nano reaction vessels for cascade reactions. Org Biomol Chem 2008;6:4315-8.

[107] Delcea M, Yashchenok AM, Videnova K, Kreft O, Möhwald H, Skirtach AG. Multicompartmental micro- and nanocapsules: hierarchy and applications in biosciences. Macromol Biosci 2010;10:465-74.

[108] Pan HM, Beyer S, Zhu Q Trau D. Inwards interweaving of polymeric layers within hydrogels: assembly of spherical multi-shells with discrete porosity differences. Adv Funct Mater 2013;23:5108-15.

[109] Chandrawati R, Caruso F. Biomimetic liposome- and polymersome-based multicompartmentalized assemblies. Langmuir 2012;28:13798-807.

[110] Champion JA, Mitragotri S. Role of target geometry in phagocytosis. Proc Natl Acad Sci U S A 2006;103:4930-4.

[111] Muro S, Garnacho C, Champion JA, Leferovich J, Gajewski C, Schuchman EH, et al. Control of endothelial targeting and intracellular delivery of therapeutic enzymes by modulating the size and shape of ICAM-1-targeted carriers. Mol Ther 2008;16:1450-8.

[112] Geng Y, Dalhaimer P, Cai S, Tsai R, Tewari M, Minko T, et al. Shape effects of filaments versus spherical particles in flow and drug delivery. Nat Nanotechnol 2007:2:249-55.

[113] Gratton SEA, Ropp PA, Pohlhaus PD, Luft JC, Madden VJ, Napier ME, et al. The effect of particle design on cellular internalization pathways. Proc Natl Acad Sci U S A 2008; $105: 11613-8$.

[114] Doshi N, Mitragotri S. Macrophages recognize size and shape of their targets. PLoS One 2010;5:e10051.

[115] Arnida, Janát-Amsbury MM, Ray A, Peterson CM, Ghandehari H. Geometry and surface characteristics of gold nanoparticles influence their biodistribution and uptake by macrophages. Eur J Pharm Biopharm 2011;77:417-23.

[116] Hutter E, Boridy S, Labrecque S, Lalancette-Hébert M, Kriz J, Winnik FM, et al Microglial response to gold nanoparticles. ACS Nano 2010;4:2595-606.

[117] Gao Y-X, Yu S-H, Cong H, Jiang J, Xu A-W, Dong W-F, et al. Block-copolymer-controlled growth of CaCO3 microrings. J Phys Chem B 2006;110:6432-6.

[118] Shchepelina O, Kozlovskaya V, Singamaneni S, Kharlampieva E, Tsukruk VV. Replication of anisotropic dispersed particulates and complex continuous templates. J Mater Chem 2010;20:6587-603.

[119] Shchepelina O, Kozlovskaya V, Kharlampieva E, Mao W, Alexeev A, Tsukruk VV Anisotropic micro- and nano-capsules. Macromol Rapid Commun 2010;31:2041-6.

[120] Kozlovskaya V, Higgins W, Chen J, Kharlampieva E. Shape switching of hollow layerby-layer hydrogel microcontainers. Chem Commun (Camb) 2011;47:8352-4.

[121] Kozlovskaya V, Yakovlev S, Libera M, Sukhishvili SA. Surface priming and the selfassembly of hydrogen-bonded multilayer capsules and films. Macromolecules 2005;38:4828-36.

[122] Shchepelina O, Lisunova MO, Drachuk I, Tsukruk VV. Morphology and properties of microcapsules with different core releases. Chem Mater 2012;24:1245-54.

[123] Lisunova MO, Holland N, Shchepelina O, Tsukruk VV. Template-assisted assembly of the functionalized cubic and spherical microparticles. Langmuir 2012:28:13345-53.

[124] Chandrawati R, Städler B, Postma A, Connal LA, Chong S-F, Zelikin AN, et al Cholesterol-mediated anchoring of enzyme-loaded liposomes within disulfidestabilized polymer carrier capsules. Biomaterials 2009;30:5988-98.

[125] Tzvetkov G, Graf B, Fernandes PAL, Fery A, Cavalieri F, Paradossi G, et al. In situ characterization of gas-filled microballoons using soft X-ray microspectroscopy. Soft Matter 2008;4:510-4.

[126] Gao Y, Zhao L, Li C, Shi G. Electrosynthesis of poly(3,4-ethylenedioxythiophene) microcups in the aqueous solution of $\mathrm{LiClO} 4$ and tri(ethylene glycol). Polymer 2006;47:4953-8.

[127] Peters RJRW, Marguet M, Marais S, Fraaije MW, van Hest JCM, Lecommandoux S. Cascade reactions in multicompartmentalized polymersomes. Angew Chem Int Ed Engl 2014;53:146-50

[128] Xiong R, Soenen SJ, Braeckmans K, Skirtach AG. Towards theranostic multicompartment microcapsules: in-situ diagnostics and laser-induced treatment. Theranostics 2013;3:141-51.

[129] Perry JL, Herlihy KP, Napier ME, Desimone JM. PRINT: a novel platform toward shape and size specific nanoparticle theranostics. Acc Chem Res 2011;44:990-8.

[130] Murthy VS, Kadali SB, Wong MS. Polyamine-guided synthesis of anisotropic multicompartment microparticles. ACS Appl Mater Interfaces 2009;1:590-6.

[131] Kohler D, Madaboosi N, Delcea M, Schmidt S, De Geest BG, Volodkin DV, et al. Patchiness of embedded particles and film stiffness control through concentration of gold nanoparticles. Adv Mater 2012;24:1095-100.

[132] Balkundi SS, Veerabadran NG, Matthew ED, Johnson GR, Lvov YM. Encapsulation of bacterial spores in nanoorganized polyelectrolyte shells. Langmuir 2009;25:14011-6.

[133] Ai H, Jones S, De Villiers M, Lvov Y. Nanoencapsulation of furosemide microcrystals for controlled drug release. J Control Release 2003;86:59-66.

[134] Minullina RT, Osin YN, Ishmuchametova DG, Fakhrullin RF. Interfacing multicellular organisms with polyelectrolyte shells and nanoparticles: a Caenorhabtidis elegans study. Langmuir 2011;27:7708-13. 